\title{
O NARRADOR RIOBALDO - PASSAR PELO ESCRITO: A TRANSMISSÃO DE EXPERIÊNCIA EM GRANDE SERTÃO: VEREDAS
}

\author{
Rosângela Ramos Corgosinho*
}

RESUM0:

\begin{abstract}
O texto é uma pesquisa sobre Grande sertão: Veredas, onde a narrativa de Guimarães Rosa é estudada através de Riobaldo. Ele é tomado como alguém que faz uma transmissão de experiência similar ao testemunho feito ao final de um tratamento psicanalítico, assim como ela é similar à narrativa que se aproxima da tradição oral e do romance moderno.
\end{abstract}

PALAVRAS-CHAVE: João Guimarães Rosa, Grande sertão: Veredas, experiência.

O narrador Riobaldo - passar pelo escrito: a transmissão de experiência em Grande sertão: veredas tem origem em um antigo projeto meu de trabalhar com 0 livro de Guimarães Rosa, projeto esse que se iniciou com uma pequena apresentação de um texto que eu elaborei, em 1987, e cujo título é: "Em-saio de psicanálise perguntas sobre técnica: ser ou não ser psicanalista ou ser e não ser psicanalista".

A palavra ensaio foi localizada como "Em-saio", na forma de um dos jogos de palavras tão comuns numa época em que líamos Lacan sobretudo através deles, como uma referência ao fato de que estamos dentro-em psicanálise - e que saímos para fora dela, para nos darmos conta da extensão da matéria que nos move.

Na ocasião, a leitura do texto de Grande sertão: Veredas era, para mim, uma espécie de paradigma das dificuldades encontradas também na leitura dos textos de psicanálise, na medida em que esta última se ordenava em torno da experiência com a clínica psicanalítica e cuja prática pessoal apenas se iniciava. Mas, de qualquer maneira, já se encontrava nesse texto uma localização do narrador do livro de

|*Mestre em Letras: Estudos Literários (Ārea de concentração: Literatura Brasileira), 2003. 


\section{EMTESE}

Belo Horizonte, v. 8, p. I-243, dez. 2004

Guimarães Rosa como aquele que faz a transmissão de uma experiência singular do sujeito em sua relação com o real, ainda que numa pequena incursão pela literatura.

Para concluir as elaborações, onde o final da análise era afirmado como um resto que fica, aquele que não se pode dizer, foi feito um esforço de aproximação da palavra real como sendo comum aos dois campos, literatura e psicanálise, numa pergunta sobre a travessia da fantasia fundamental, aí apresentada como fantasma: "Digo: o real não está na saída nem na chegada: ele se dispõe para a gente é no meio da travessia"1 - do fantasma? (o texto acrescentava esta última pergunta).

E após a proposta de uma inversão dos lugares entre analisante e analista, sendo Riobaldo tomado como o nome do analista, aparecia a frase de fechamento do texto: "Riobaldo, a colheita é comum, mas o capinar é sozinho".2

Essa mesma frase é tomada como a epígrafe do novo trabalho que se apresenta agora em forma de uma dissertação. Nesta, procuro fazer uma demonstração de que é pelo tratamento da linguagem que se pode aproximar do impossível, situado em campos de diferentes práticas: literatura e psicanálise.

É a partir de constatações desse teor que penso ser possível localizar Riobaldo como um narrador oriundo da tradição das grandes narrativas orais, aquele que faz a transmissão de experiência como a que se efetua pela voz anônima nas comunidades de cunho artesanal, vindo a subjetivar essa tradição numa narrativa próxima da enunciação do sujeito que vive os problemas existenciais próprios à solidão do romance moderno, e, finalmente, ultrapassa esse plano, passando a constituir o narrador da singular relação entre sujeito e objeto, numa transmissão que é similar àquela que se dá ao final de uma análise.

Essa localização do narrador indica que a linguagem literária também se presta à transmissão de uma relação inédita entre o sujeito e o real, instaurando um novo discurso que contém esse real no escrito. Contida no próprio título da dissertação, a expressão "passar pelo escrito" vem demonstrar, pois, que existe algo mais além do escrito e que se faz passar por ele, ou seja, o real que cessa de não se escrever num encontro contingente. Esse encontro, enquanto cerne de uma transmissão de exceção, se apresenta, pois, ao lado da transmissão de outras experiências: tanto a que se aproxima da tradição das narrativas orais, onde se pode 
ver a presença dos gêneros épico e lírico, assim como da narrativa do sujeito solitário do mundo moderno, aquele que nos fala na concepção de um romance. Isso quer dizer que a polivalência do discurso de Grande sertão: veredas é a base de onde parto para fazer a pesquisa da construção da narrativa do livro.

Além dos pontos demarcados, existe a presença da voz narrativa, transmissão exemplar de como a voz-objeto se faz passar por um escrito, em que também se veicula a oralidade, onde não se transmite apenas a voz, mas ainda a gestualidade que imprime ao relato o movimento enquanto presença do sujeito, assim como se transmite a voz da tradição cultural. Ou seja, também a voz, que se apresenta nessa narrativa, se torna exemplar da transmissão que é feita pelo narrador Riobaldo como possuindo três estatutos diferentes: a voz narrativa da tradição oral, a voz do sujeito da narrativa do romance e a voz objeto que se fazem passar pelo escrito de Grande sertão: Veredas. É a partir dessas afirmativas que a "Canção de Siruiz" foi tomada como um centro paradigmático para a localização dessa voz, assim como da estratégia narrativa utilizada no livro.

Como se pode ver, trata-se do estudo da narrativa de Guimarães Rosa, na vertente de uma mescla que se transmite o tempo todo e onde acrescentamos a contribuição de uma leitura, em psicanálise, como um saber de exceção que também se transmite na voz do narrador. Esta é a inserção de um novo detalhe na leitura de um livro que sugere a polifonia das vozes, tantas são as possibilidades de leitura que o seu texto oferece. E se essa é uma marca observada por inúmeros estudiosos do livro, como Antonio Candido, Ettore Finazzi-Agrò, David Arrigucci Júnior, entre outros, é porque em cada leitura observa-se o traço da particularidade do novo leitor.

Se de um 1ado, esse aspecto de uma $0 b r a-m u n d o^{3}$ é um incentivo a mais para que possamos abordá-la pela ótica do ofício de cada um, por outro, ele constitui uma dificuldade a mais para estudar sua narrativa, na medida em que a pesquisa da fortuna crítica se torna também um trabalho de seleção, entre muitos estudos importantes, recaindo-se num recorte que contenha pontos elucidativos para o referencial trabalhado. Mesmo assim, dentro dessa seleção, ainda foi necessário deixar de lado vários estudos preciosos que apenas iriam reiterar as conclusões das contribuições citadas. Nessa perda que toda escolha implica, é claro, subjetiva-se a leitura de Grande sertão: veredas do ponto-de-vista de cada pesquisador. 


\section{EMTESE}

Belo Horizonte, v. 8, p. I-243, dez. 2004

No que diz respeito à transmissão de experiência, basicamente apoiei-me nos textos de Walter Benjamin que falam sobre essa transmissão na tradição oral e nos textos de Jacques Lacan, bem como de alguns dos seus leitores, que abordam a transmissão de experiência que é feita no dispositivo do passe. Além disso, busquei leituras que permitissem situar o estatuto do narrador na especificidade da personagem Riobaldo, assim como trabalhos que auxiliassem a demonstração de como a tradição é subjetivada por esse narrador.

No mais, trata-se apenas de uma conversa entre a literatura e a psicanálise, num encontro contingente, entre esses dois campos, através da narrativa de Riobaldo, a criatura de Guimarães Rosa, que possui a mesma voz de independência excepcional das personagens de Dostoiévski. ${ }^{4}$ É através dessa voz que nos é transmitida, num escrito, a experiência de vida de um singular narrador que nos transmite ainda a experiência de um saber de exceção sobre a falta.

$E$, se é uma conversa que mantém o tom de um diálogo constante entre a literatura e a psicanálise, é porque esse é um diálogo que circula entre a transmissão localizada na tradição literária e aquela dos dispositivos da psicanálise, principalmente o dispositivo do passe, buscando localizar pontos de aproximação, em meio às diferentes estratégias de tratamento do real. Trata-se, sem dúvida, de um trabalho de retomada da narrativa de Guimarães Rosa, em Grande sertão: Veredas, através da voz-narrativa construída para a personagem Riobaldo, narrador que subjetiva a tradição, pelo discurso significante do sujeito, em torno do objeto causa Diadorim.

E é exatamente por instaurar uma narrativa, em que a falha na linguagem está incluída, que Grande sertão: Veredas é considerado, nesse estudo, como constituindo um passo a mais na literatura, ao formular um discurso novo, numa nova alíngua inventada, ou seja, uma língua que inclui os objetos nas palavras. Ou seja, tratase de "passar pelo escrito" o que seria inicialmente "canto, mito falado, procissão dramática", desde que é feita "a acomodação de restos", dos objetos, na linguagem literária. ${ }^{5}$

São essas formulações que tornam o livro de Guimarães Rosa exemplar de uma transmissão de exceção, que se faz ao lado da transmissão de experiência próxima à que é feita nas grandes narrativas orais, que, por sua vez, se faz passar pelo escrito do sujeito do romance do mundo moderno, esse sujeito solitário das grandes cidades que tenta apagar seus rastros em meio às grandes guerras que silenciam. 
NOTAS:

1. ROSA, 1984, p. 60.

2. Ibidem, p. 54.

3. FINNAZI-AGRÕ, 2001.

4. BAKHTIN, 1981, p. 2.

5. LACAN, 2001, p. 11-12.

\section{ABSTRACT :}

The text is a research about Grande sertão: veredas, where Guimarães Rosa's narration is studied through Riobaldo. He is seen as someone who makes an experience's transmission similar to the testimony made in the end of a psychoanalytic treatment. It is similar to the narration which approaches the oral tradition and the modern novel.

KEY WORDS: João Guimarães Rosa, Grande sertão: veredas, experience.

\section{REFERÊNCIAS BIBLIOGRÁFICAS}

BAKHTIN, Mikhail. Problemas da poética de Dostoiévski. Rio de Janeiro: Editora Forense, 1981. 239 p.

CORGOSINHO, Rosângela Ramos. Em-saio de psicanálise: perguntas sobre técnica. Belo Horizonte: Fórum do CPMG, 1987, 4 f. Mimeografado.

FINAZZI-AGRÒ, Ettore. Um lugar do tamanho do mundo: tempos e espaços da ficção em João Guimarães Rosa. Belo Horizonte: Editora UFMG, 2001. 201 p.

LACAN, Jacques. Autres écrits. Paris: Seui1, 2001. 591 p. ROSA, João Guimarães. Grande sertão: Veredas. 20. ed. Rio de Janeiro: Nova Fronteira, 1984. 568 p. 